\title{
Visual acuity in a national sample of 10 year old children
}

\author{
SARAH STEWART-BROWN AND NEVILLE BUTLER \\ From the Department of Child Health, University of Bristol
}

SUMMARY The prevalence of defects of visual acuity among the 10 year old children in the 1970 birth cohort was $22 \cdot 1 \%$, but only in one third of these children was the defect more severe than $6 / 9$. Defects were more common among girls. The relation of defects to social class was complex. Comparison with data collected on the children of the 1958 cohort when they were 11 years old suggests that although the prevalence of $6 / 9$ visual acuity has remained constant over the last decade, the prevalence of more severe defects has declined from $12 \cdot 9 \%$ to $7 \cdot 3 \%$. These findings have a number of implications for the provision of screening programmes and of ophthalmic services for children.

The National Health Service expends considerable resources on seeking and treating eye defects in children. Babies are screened for visual perception in order to identify those who are blind or partially sighted. Preschool children are screened for squint in order to institute early treatment which may prevent the development of amblyopia. Schoolchildren are screened principally to identify refractive errors because it is believed that such defects may interfere with a child's development, particularly in the educational field.

It is important to monitor the prevalence of visual defects in children for several reasons: firstly, to detect epidemics of conditions such as retrolental fibroplasia which may have a preventable aetiology; secondly, to be able to evaluate the efficacy of preventive programmes such as those for screening and treatment of squint; and, thirdly, to permit rational management of vision screening programmes in schoolchildren and of the diagnostic services that are required as a backup.

In this paper we present information on the prevalence of defects of visual acuity among the 10 year old children of the 1970 birth cohort. This data set comprises a representative sample of 13000 children, similar to that of the 1958 cohort for which data on visual defects have already been published. ${ }^{1-3}$ The information presented will be of value to those who are attempting to rationalise school eye services and vision screening programmes for schoolchildren. It provides a useful guide for the evaluation of screening programmes for squint.
The data set is not appropriate for identifying changes in prevalence of serious but rare ophthalmic conditions in children, and this paper does not make any attempt to do this.

\section{Methods}

The Child Health and Education Study is the third of the British national birth cohort studies. It began with a survey of all British births during one week in April 1970. In 1975 and again in 1980 members of the cohort, except those living in Northern Ireland, were retraced through schools and surveyed with the help of health visitors, child health doctors, and teachers.

In the 1980 study, when the children were 10 years of age, a health visitor interviewed the child's parents at home, asking a wide range of questions on social and family circumstances and on the child's current health and past medical history. This parental questionnaire contained details of the occupation of the child's father (or father figure) which have been classified according to the Registrar General's Classification of Occupations $1980 . .^{4}$ At the same time the child's school doctor completed a medical questionnaire on the child in which were recorded the results of an extensive medical examination, including visual acuity testing.

Tests for visual acuity were carried out under conditions similar to those in which children are routinely screened in clinics and schools. Instructions were given with the questionnaire to test the child's distant vision using a Snellen chart, by standing the 
child in a good light $20 \mathrm{~m}$ from the chart and covering first one eye and then the other. If a Snellen chart was not available, or its use was inappropriate, the doctor was asked to record the alternative used. Of the children with satisfactory results $80.9 \%$ were tested with Snellen charts; in $7.6 \%$ Stycar test types were used; Sheridan-Gardiner test types accounted for another $5.0 \%$; and a small group of children (3.0\%) were tested with other apparatus such as Keystone. Near vision was tested using a Sheridan-Gardiner near vision chart which was provided with the questionnaire. ${ }^{1}$ Instructions were given to hold the latter at a comfortable distance not more than 10 in. from the eye, in a good light, testing each eye separately.

Gradations of visual acuity on the Sheridan-Gardiner chart are as follows: $6,9,12,18$, $24,36,60$, and worse than 60 . These gradations correspond to those on the Snellen chart $(6 / 6,6 / 9$, $6 / 12,6 / 18,6 / 36,6 / 60,>6 / 60)$ in that angle subtended at the eye by the letters in each line of the Snellen Chart at $20 \mathrm{~m}$ is approximately the same as that subtended by the letters in the corresponding line of the Sheridan-Gardiner chart at 10 in.

The medical examination included an assessment of signs of the onset of puberty, and the findings were recorded in the medical questionnaire.

Specific diagnostic information about the nature of any visual abnormality was requested for all children. This item has yielded useful information for children with severe defects (for example, cataracts), but the response was incomplete for children with milder defects; accurate diagnostic grouping of children with defects could therefore not be made. However, because some common eye conditions cause characteristic and moderately distinctive patterns of loss of visual acuity, we have identified different categories of defect, some of which can be related to specific diagnoses. These categories are:

defects of distant vision and perfect near vision (isolated distant vision defects);

defects of near vision and perfect distant vision (isolated near vision defects);

defects of both near and distant vision (mixed defects).

Defects have been grouped according to their severity, and these groups have been labelled arbitrarily: minimal $(6 / 9,9)$; mild $(6 / 126 / 1812,18)$; moderate $(6 / 246 / 3624,36)$; and severe $(6 / 60<$ $6 / 60)$. Children with bilateral defects of varying severity have been categorised according to the level of defect in the better eye, and children with mixed defects have been classified according to the severity of their distant vision defect. Children who have significant mixed defects in one eye $(\leqslant 6 / 24)$ and a minimal defect $(6 / 9$ or 9$)$ in the other have been categorised as having unilateral defects.

This classification was developed, firstly, in order to be able to identify children with minimal defects; secondly, to be able to calculate the number of children whose defects would not have been detected $I$ if they had undergone only distant vision screening; and, thirdly, to be able to pick out children with $\underset{?}{\overrightarrow{.}}$ defects to which it is possible to attach a probable diagnosis.

The characteristic diagnosis among children with more than minimal defects of distant vision and perfect near vision is myopia. Although other types of defect may be included in these categories, the prevalence of myopia is so much greater than that of \& all these other defects put together ${ }^{2}$ that it is $\vec{\circ}$ reasonable to use these categories as a proxy for myopia. In the same way, unilateral mixed defects, which are of more than minimal severity, can be used as a proxy for amblyopia. The latter categories are less good proxies than those which can be used for myopia since not only will children with conditions of other aetiology be included (for example, ey ${ }^{\circ}$ injuries) but amblyopes with a significant degree of $\overrightarrow{0}$ hypermetropia or astigmatism in the good eye will b요 응 excluded.

\section{Results}

RESPONSE RATE

Parental interviews were completed for 1378 or children and medical examinations on 13 723; a total of 13871 children participated in one or other aspect of the health survey, an estimated $86.7 \%$ of survivors from the original birth cohort.

Satisfactory visual acuity data were not available for all children who underwent medical examinations. In some, these tests were not carried out at all, in others the tests were completed partially (ie, distant vision only) or conducted inadequately (ie, both eyes tested together). After excluding unsatisfactory results, visual acuity data on 12853 children were available for analysis.

In the future, when the records of the children at birth and at age 5 have been linked to the ten year data, it will be possible to estimate accurately bias in $\frac{\mathrm{O}}{3}$ the data set due to children who were not surveyed.

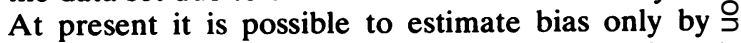
comparing the group of children for whom we have $\frac{D}{2}$ visual acuity data with the entire group for whom we have health data. Data were obtained on a $N$ significantly higher proportion of children in the non manual classes, but the range is not great: $94.0 \%$ of social class I children falling to $90 \cdot 5 \%$ of social class $V \mathrm{~W}$ children. As might have been anticiated, only a small 
proportion of ESN(S) children (29.5\%) were able to complete the tests, but $91.7 \%$ of children classified ESN(M) managed to do so.

The median age at which children underwent vision screening was 10.3 years but the age distribution was positively skewed with a range of 9.9-11.7 years.

PREVALENCE OF VISUAL DEFECTS

Prevalence rates for this sample of 10 year old children are presented in table 1 . Twenty-two per cent of all children had some defect of vision, but only $7.6 \%$ had more than a minimal defect and $4.5 \%$ had such defects in both eyes. As few as $1.8 \%$ of children had an unaided visual acuity which was likely to cause them difficulty in reading the blackboard from the front of the classroom (6/24 or worse in both eyes).

SEX DIFFERENCES AND CHANGES ASSOCIATED WITH PUBERTY

Visual defects were more common in girls (23.3\%) than in boys $(20.9 \%)$. This was true for both children who had entered puberty and those who were prepubertal (table 2). For both sexes the prevalence of defects was between 1 and $2 \%$ higher in children who had entered puberty than in prepubertal children. This excess could be accounted for by defects characteristic of myopia (table 3 ) and is consistent with the clinical view that myopia commonly develops at puberty. The excess of defects among the prepubertal girls was not due to defects characteristic of myopia since the prevalence of the latter was the same in both sexes. These analyses suggest that visual defects were commoner in girls at 10 years of age, partly because of the earlier onset of puberty in girls with the concomitant development of myopia, and partly due to an excess of defects other than myopia which were present both before and after puberty.
Table 2 Sex of child, pubertal status, and prevalence of vision defects

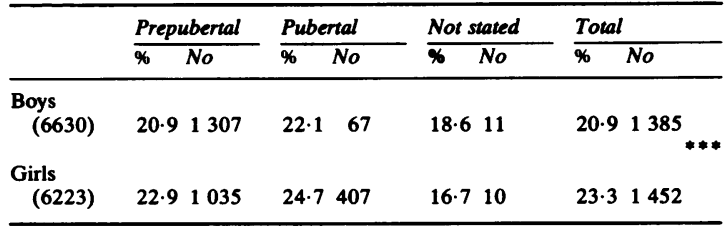

*** $\mathrm{p}<0.001\left(\mathrm{X}^{2}, \mathrm{df}=1\right.$ for difference between prevalence of defects in boys and girls)

Table 3 Proportion of children with Isolated distant vision defects (proxy myopia)

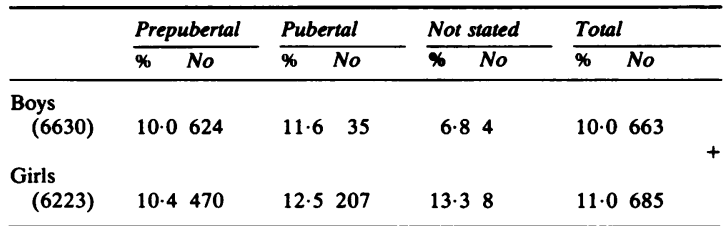

$+\mathrm{p}=\mathrm{ns}\left(\mathrm{X}^{2}, \mathrm{~d} \mathrm{f}=1\right.$ for difference between prevalence of defects in boys and girls)

SOCIAL CLASS DIFFERENCES

The prevalence of visual defects showed some variation with social class (table 4). Those in social class $\mathrm{V}$ had the highest prevalence $(25 \cdot 7 \%)$ and those in social class II the lowest $(20 \cdot 7 \%)$. However, there was no consistent trend across the social classes, and no statistically significant difference could be shown when prevalence in all the manual classes combined $(22 \cdot 1 \%)$ was compared with that in all non manual classes combined $(21 \cdot 4 \%)$.

We were unable to find a social class difference in the prevalence of defects characteristic of amblyopia

Table 1 Prevalence (\%) of vision defects at 10 years

\begin{tabular}{|c|c|c|c|c|c|c|c|}
\hline \multirow{2}{*}{$\begin{array}{l}\text { Category of } \\
\text { defect }\end{array}$} & \multicolumn{2}{|c|}{ Distant vision only } & \multicolumn{2}{|c|}{ Near vision only } & \multicolumn{2}{|c|}{ Mixed defects } & \multirow[b]{2}{*}{ Total } \\
\hline & Bilateral & Unilateral & Bilateral & Unilateral & Bilateral & Unilateral & \\
\hline $\begin{array}{l}\text { Minimal } \\
(6 / 9 \text { or } 9) \\
\text { Mild }\end{array}$ & 3.7 & 3.6 & 1.4 & 2.0 & 2.9 & 0.8 & 14.5 \\
\hline $\begin{array}{l}(6 / 126 / 18: \quad 12,18) \\
\text { Moderate }\end{array}$ & $1 \cdot 3$ & 0.8 & 0.1 & $0 \cdot 1$ & $1 \cdot 3$ & 0.8 & $4 \cdot 5$ \\
\hline $\begin{array}{l}(6 / 24 \text { 6/36: 24, 36) } \\
\text { Severe }\end{array}$ & 0.7 & $0 \cdot 1$ & 0.02 & - & 0.7 & 0.8 & $2 \cdot 3$ \\
\hline $\begin{array}{l}(6 / 60<6 / 60) \\
\text { Total }\end{array}$ & $\begin{array}{l}0.2 \\
5.9\end{array}$ & $\begin{array}{l}0.02 \\
4.5\end{array}$ & $\overline{1.5}$ & $\overline{2 \cdot 1}$ & $\begin{array}{l}0 \cdot 2 \\
5 \cdot 1\end{array}$ & $\begin{array}{l}0 \cdot 4 \\
2 \cdot 8\end{array}$ & $\begin{array}{r}0 \cdot 8 \\
22 \cdot 1\end{array}$ \\
\hline
\end{tabular}

$(\mathrm{N}=12853)$ 
(Table 5). Although identification of this condition is far from precise, these data suggest that there is unlikely to be a clinically significant association between social class and amblyopia.

Defects characteristic of myopia were more common among children in social class I (table 6), but there was little variation in prevalence across the other social classes. This finding has been observed consistently in previous birth cohort studies. ${ }^{25}$

Table 4 Vision defects and social class

\begin{tabular}{lcl}
\hline Social class & Number of children & \% with visual defects \\
\hline I & 715 & $23 \cdot 7$ \\
II & 2715 & $20 \cdot 7$ \\
III MN & 1053 & $21 \cdot 8$ \\
III M & 5033 & $21 \cdot 4$ \\
IV & 1303 & $23 \cdot 6$ \\
V & 436 & $25 \cdot 7$ \\
NFF & 912 & $23 \cdot 9$ \\
Not specified & 686 & $23 \cdot 3$ \\
All non manual & 4483 & $21 \cdot 4$ \\
All manual & 6772 & $22 \cdot 1^{*}$
\end{tabular}

* $p=0.05\left(X^{2} d f=6\right)$

$\mathrm{NFF}=$ no father figure

Table 5 Prevalence of proxy amblyopia by social class (unilateral mixed defects where distant vision is $6 / 12$ or worse)

\begin{tabular}{lrl}
\hline Social class & $n$ & \% with defects \\
\hline I & 715 & $2 \cdot 1$ \\
II & 2715 & $1 \cdot 7$ \\
IIIN & 1053 & $1 \cdot 7$ \\
IIIM & 5033 & $2 \cdot 1$ \\
IV & 1303 & $2 \cdot 4$ \\
V & 436 & $2 \cdot 5$ \\
No father figure & & 1.5 \\
and not specified & 1598 & $1 \cdot 5$ \\
\hline
\end{tabular}

$p=N S\left(X^{2} d f=6\right)$

Table 6 Prevalence of proxy myopia by social class (bilateral distant vision defects 6/12 or worse in better eye)

\begin{tabular}{lll}
\hline Social class & \multicolumn{1}{l}{$n$} & \% with defects \\
\hline I & 715 & 5.0 \\
II & 2715 & $2 \cdot 3$ \\
IIIN & 1053 & $2 \cdot 7$ \\
IIIM & 5033 & $1 \cdot 8$ \\
IV & 1303 & $1 \cdot 6$ \\
V & 436 & $2 \cdot 3$ \\
No father figure & 1598 & $2 \cdot 2$ \\
and not specified & & \\
\hline p $0.001\left(\mathrm{X}^{2} \mathrm{df}=6\right)$ &
\end{tabular}

SECULAR TRENDS

The prevalence of defects in this study is compared with prevalence rates published from the 1958 birth $ᄋ$ cohort $^{3}$ in table 7. The latter were gathered in 1969 on children aged 11 years. The visual acuity data collected in the two studies are likely to be comparable as the methodologies were very similar. $I$ But in any comparisons which can be drawn between $\cong$ the two an allowance must be made for the one year difference in age and thus for the likelihood that $a \Rightarrow$ higher proportion of the 1958 cohort had entered $\stackrel{?}{+}$ puberty.

The overall prevalence of distant vision defects $\frac{\bar{O}}{\bar{N}}$ (both isolated distant vision defects and mixed $\frac{\text { s? }}{5}$

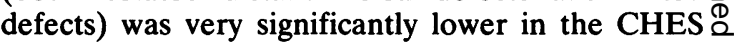
cohort $(18.5 \%)$ than in the earlier study $(22.8 \%)$ \% $(\mathrm{p}<0.00001)$. The prevalence of minimal defects $\vec{\circ}$ was actually higher in the CHES cohort than in the earlier study; thus the overall reduction was due $\vec{\omega}$ entirely to a decrease in more severe defects $(12.9 \%$ o in the NCDS cohort and $7 \cdot 3 \%$ in the CHES cohort). $\stackrel{\odot}{\circ}$ Most, but not all, of this difference was due to a $\stackrel{?}{\omega}$ difference in prevalence of isolated distant vision 0 defects, which could have been accounted for by the ? development of myopia at puberty. However, the $\vec{e} \overrightarrow{0}$ was also an intercohort difference in the prevalens 0 of other defects: $6 \cdot 8 \%$ of children in the 1958 cohont had significant visual defects of the sort which coufe $\vec{c}$ not be due to uncomplicated myopia, in contrast $4.1 \%$ of children in the 1970 cohort $(p<0.0019$ Three per cent of the 1958 cohort had significami $\vec{\varphi}$ unilateral mixed defects (proxy amblyopiā) compared with only $2.0 \%$ of the 1970 cohort.

In the absence of evidence that conditions other than myopia commonly develop at the time of onset of puberty, our findings suggest that there has been a significant reduction in prevalence of the sort of visual defects that are likely to cause disability in children.

The prevalence of near vision defects (isolated near vision defects and mixed defects combined) was $12.4 \%$ in the 1958 cohort and $11.4 \%$ in the 1970 cohort. This difference is significant only at the $5 \%$ \% level.

\section{Discussion}

Surveys of this type attract criticism because of the

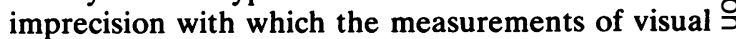
impairment were made. There is no doubt that visual $\frac{T}{2}$ acuity charts used by a variety of clinicians in a variety of settings provide a very blunt instrument with which $N$ to measure visual function.

Several types of measurement error are common in vision testing; some lead to over estimation of visual $\omega$ function (reduced distance from the chart, 
incomplete coverage of the eye not being tested), others to an underestimate (inadequate lighting, poor concentration). Any one of these errors could have led to bias in the results we have presented, but because common errors lead to both over and underestimates, these effects will to some extent have cancelled each other out.

Detailed ophthalmological investigation of 13000 children can be undertaken only at very great expense, and in this survey precise measurements were not practicable. Nevertheless the study does provide information which should be of interest to specialists in community medicine responsible for child health services and to practising ophthalmologists.

For example, data have been presented on which referral rates from school screening programmes can be calculated. If all children with less than perfect visual acuity are referred after screening, provision must be made for one in five children to be seen in school eye clinics. If screening is undertaken annually and this referral level is used, one in five children will need to be seen every year. If children with defects of $6 / 12$ or worse are referred, between 1 in 10 and 1 in 20 of the school population will present for ophthalmological investigation. School screening programmes which do not include near vision screening will miss the $3.6 \%$ of children who have isolated near vision defects. As the majority of these have only a minimal defect the omission may not be important.

Clearly, the optimal type of screening test and the optimal referral level must depend not just on the numbers of chldren who may be referred but also on the importance of the defect and the possibility of providing effective treatment. One recent study ${ }^{6}$ has been unable to show any disability associated with $6 / 9$ vision, and in the absence of evidence that the condition is important it is a considerable waste of scarce resources to provide diagnostic services for the large number of children with this level of acuity. Imprecision of measurement is unlikely to have had a significant influence on the changes we have identified between 1969 and 1980 . Visual acuity testing in schools has changed little over the period, and errors which were reported to be common in $1969^{1}$ were still common in 1980 . Because of this we can paradoxically have more confidence in the secular changes we have documented than in the precise estimates of defect prevalence.

The data presented permit calculations to be made on the yield from vision screening programmes of clinically significant defects. We have documented a fall in the prevalence of the latter of an early $50 \%$. During this period the prevalence of minimal defects has increased. Thus the yield of clinically significant defects from the same screening programme would have been much higher in 1969 than it would have been in 1980. In another 10 years the cost effectiveness of the same programme may have reduced still further.

Screening programmes such as that for squint which are designed to prevent the development of visual impairment should produce a measurable change in the prevalence of that impairment. It is impossible without more precise diagnostic information to identify the cause or causes of the secular fall in visual defect prevalence that we have identified, but the results presented are quite compatible with a fall in prevalence of amblyopia. They provide some measure of the magnitude of effect which such screening programmes might be having and should give encouragement to those providing the programmes until more precise studies are undertaken.

The health aspect of the 10 year follow up was funded by a grant from the Department of Health and Social

Table 7 Secular changes in distant vision acuity

\begin{tabular}{|c|c|c|c|c|c|c|c|c|}
\hline \multirow[b]{4}{*}{ Defects } & \multirow{2}{*}{\multicolumn{4}{|c|}{$\begin{array}{l}1969 \\
\text { NCDS } 11 \text { year olds } \\
(n=12793) \\
\text { Proportion of children }\end{array}$}} & \multirow{2}{*}{\multicolumn{4}{|c|}{$\begin{array}{l}1980 \\
\text { CHES } 10 \text { year olds } \\
(n=12853) \\
\text { Proportion of children }\end{array}$}} \\
\hline & & & & & & & & \\
\hline & \multicolumn{2}{|c|}{$\begin{array}{l}\text { With any distant } \\
\text { vision defect }\end{array}$} & \multicolumn{2}{|c|}{$\begin{array}{l}\text { With isolated distant } \\
\text { vision defect }\end{array}$} & \multicolumn{2}{|c|}{$\begin{array}{l}\text { With any distant } \\
\text { vision defect }\end{array}$} & \multicolumn{2}{|c|}{$\begin{array}{l}\text { With isolated distant } \\
\text { vision defect }\end{array}$} \\
\hline & $\%$ & No & $\%$ & No & $\%$ & No & $\%$ & No \\
\hline $\begin{array}{l}\text { Minimal }(6 / 9) \\
\text { Mild }(6 / 126 / 18) \\
\text { Moderate and severe }(\geqslant 6 / 24) \\
\text { Totals }\end{array}$ & $\begin{array}{r}9.9 \\
6.9 \\
6.0 \\
22.8\end{array}$ & $\begin{array}{r}1264 \\
889 \\
770 \\
2923\end{array}$ & $\begin{array}{r}7 \cdot 5 \\
3 \cdot 3 \\
2 \cdot 8 \\
13 \cdot 5\end{array}$ & $\begin{array}{r}960 \\
417 \\
356 \\
1733\end{array}$ & $\begin{array}{r}11 \cdot 1 \\
4 \cdot 3 \\
3 \cdot 0 \\
18 \cdot 5\end{array}$ & $\begin{array}{r}1432 \\
557 \\
389 \\
2378\end{array}$ & $\begin{array}{r}7 \cdot 4 \\
2 \cdot 2 \\
1 \cdot 0 \\
10 \cdot 7\end{array}$ & $\begin{array}{r}944 \\
278 \\
125 \\
1397\end{array}$ \\
\hline
\end{tabular}

For levels of statistical significance please see text 
Services to the Department of Child Health, University of Bristol. Additional financial support was received from the National Institute of Health, USA. We gratefully acknowledge the widespread cooperation of all specialists of community medicine, clinical medical officers, and health visitors who have made this study possible. In addition, we thank all participating children and their parents. The editing and coding of this study was carried out by a dedicated body of clerical staff, some of whom were employed on a programme funded by the Manpower Services Commission.

No reprints available.

\section{References}

${ }^{1}$ Peckham C, Adams B. Vision screening in a national sample of 11 year old children. Child Care, Health and Development, 1975.

${ }^{2}$ Peckham C, Gardiner P, Goldstein H. Acquired myopia in 11 year old children. $\mathrm{Br}$ Med J 1977, i: 542-4.

${ }^{3}$ Alberman E, Butler N, Gardiner P. Children with squints. A handicapped group? The Practitioner 1971; 206: 501-6.

${ }^{4}$ Office of Population Censuses and Surveys. Classification of occupations. London: HMSO, 1980.

${ }^{5}$ Douglas JWB, Ross JM, Simpson HR. The ability and attainment of short sighted pupils. J Roy Statist Soc 1967; 130: 479-90.

${ }^{6}$ Stewart-Brown S, Haslum M, Butler N. Education attainment in 10 year old children with treated and untreated defects of visual acuity. Dev Med Child Neurol, in press, 